\title{
Rear Wheel Drive Recumbent Bicycle for Urban Transportation in a Tropical Emerging Country
}

\author{
Bambang Suhardi ${ }^{1}$, Ilham Priadythama ${ }^{2, *}$, and Pringgo Widyo Laksono ${ }^{3}$ \\ ${ }^{1}$ Laboratory of Work System Design and Ergonomics, Industrial Engineering Department, Universitas \\ Sebelas Maret, Ir. Sutami Street No. 36A, Jebres Surakarta, Indonesia. \\ ${ }^{2}$ Laboratory of Product Planning and Design, Industrial Engineering Department, Universitas Sebelas \\ Maret, Ir. Sutami Street No. 36A, Jebres Surakarta, Indonesia. \\ ${ }^{3}$ Center of Technological Study and Development and Industrial Collaboration, Universitas Sebelas \\ Maret, Ir. Sutami Street No. 36A, Jebres Surakarta, Indonesia.
}

\begin{abstract}
Bicycle for urban transportation in emerging countries still relies on "upright" bicycle which is unchanged since the $20^{\text {th }}$ century. In a tropical emerging country such as Indonesia, a bicycle must be ergonomically designed because it may be used in a long run. On the other hand, bicycle rider may face various traffic conditions. Additionally, weather makes trip become heavy and takes a lot of energy. This research aims to develop and test a new bicycle concept for an urban transportation in the tropical emerging country. A multi-criteria decision method was used to select a right bicycle concept. Then the concept was detailed into a bicycle design. We used biomechanics model and simulated finite element method to verify its frame strength. After the design verified, we built a full bicycle prototype and compare it with a commercially available urban bicycle with equal specifications. The comparison tests include physiological tests and a subjective test for several terrain and traffic conditions. The new concept is an ergonomic bicycle based on rear wheel drive recumbent bike. Based on the overall test result, it can be concluded that the new bicycle concept is promising and still appropriate for the next development.
\end{abstract}

\section{Introduction}

A Bicycle is a clean transportation mode which can significantly reduce air pollution in an urban area [1]. Study of bicycle development for an alternative transportation and sport has been being conducted for many years and has resulted more aerodynamic and ergonomic bicycle [2]. The application of bicycle sharing system has also done for several cities such as in America and Australia [3]. However, bicycle for urban transportation in emerging countries still relies on "upright" bicycle which is unchanged since the $20^{\text {th }}$ century. In a tropical emerging country such as Indonesia, a bicycle is used to deliver worker from smalltown around the city to the center of the city. For that purpose, a bicycle must be

\footnotetext{
* Corresponding author: priadythama@gmail.com
} 
ergonomically designed because it may be used for a long run and high-frequency, otherwise some issues may occur for bicycle overuse. For a long run riding, bicycle rider may face Carpal Tunnel Syndrome risk [4]. Spinal and pelvis disorder may also be affected by high-frequency riding [5]. Moreover, upright posture for high-frequency bicycle pedalling may cause urogenital disorder and even infertility [6].

From outskirt to city, bicycle rider may face various traffic conditions from long quiet to very dense with "stop and go" road. Additionally, the distance and temperature make the trip become heavy and takes a lot of energy and progressively reduce physical endurance [7]. When it combined with low infrastructure quality, safety risk may increase [8].

This research aims to develop and test a new bicycle concept for an urban transportation in the tropical emerging country. Many types of bicycle existed with their advantages and weaknesses [9], then the right type must be chosen for a design reference. A multi-criteria selection approach is needed since there are many criteria related to bicycle usage [10]. The reference must be developed into a prototype and evaluated to see its performance.

\section{Methods}

Our research consists of four major stages. The first stage is Concept Selection. In this stage, Criteria were collected from 22 scientific resources, then reduced and confirmed by 8 experts consist of enthusiast user, bicycle technician, academician, and bicycle research team. The criteria were confirmed using there point scale valuation and cut off point method [11], then remaining criteria were weighted using the valuation. Bicycle type concepts from 4 sources $[9,12,13,14]$ were collected as reference alternatives. The reference may be selected from non-urban bicycle type. Then the alternatives were scored to find the top three concepts. After that, using the possibility of further development consideration [15], and by improving weak criteria, the best reference concept was chosen. Finally, the urban bicycle concept and its riding posture were visualized using Catia V5.

The next stage is Detail Development. Visual design cannot be directly transformed into a prototype. It must be detailed first with specifications. We choose a collaborative approach which involved custom bicycle manufacturer to specify the proposed urban bicycle components. After that, there is a Design Verification stage. In building a bicycle prototype, frame design is very crucial. In this stage, we didn't want to have a complex frame. A simple but safe construction is our priority. A biomechanics model of bicycle rider was used to determine input force parameter for finite element simulation. We compared circular and rectangular cross-section. We also compared several cross-section sizes of the frame to find the best (strong but lightweight) frame. The simulation was conducted in Autodesk Inventor 2016.

The last stage is Prototype Evaluation. In this stage, we built a rideable urban bicycle concept prototype. In order to evaluate its performance, we conducted a comparison test between the concept and commercially available urban bicycle (a modern roadster type). We carefully selected the brand and model type to provide the closest specification to the concept. Then we designed a test with 4 type of terrains, a light traffic flat road (LTFR), a light traffic, up and down-road (LTUR), a heavy traffic flat road (HTFR), and a damaged

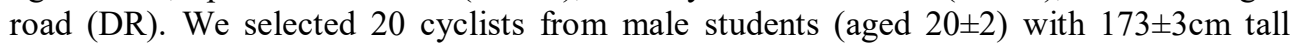
height. For the test, we compute Cardiovascular Load (\%CVL) of the subjects separately for each road type. \%CVL can be a measure of workload of light and heavy activity [16]. $\% \mathrm{CVL}$ can be computed by following formula:

$$
\% C V L=\frac{100 \%(\text { Working Pulse Rate }- \text { Initial Pulse Rate })}{\text { (Maximum Pulse Rate }- \text { Initial Pulse Rate })}
$$




\section{Result and Analysis}

\subsection{The Best Concepts Reference}

There are top three urban bicycle concept reference, Modern Roadster, 27" Mountain Bike, and Short Wheelbase Recumbent Bike. More detail information can be read in our previous research [17]. Bicycle for the tropical emerging country is characterized by almost all of the criteria, for example, heavy traffic, the bicycle must be easy to handle or good in maneuver, for long distance riding in hot temperature, the bicycle must be efficient in pedalling and comfort in riding. After applying further development consideration which may improve the weak criteria score of the three reference, the total final scores become 2.7823 for Modern Roadster, 2.6973 for 27'MTB, and 2.7857 for Short Wheelbase Recumbent Bike. Therefore, Short Wheelbase Recumbent Bike is the chosen reference for new urban bicycle concept.

\subsection{Concept Visualization}

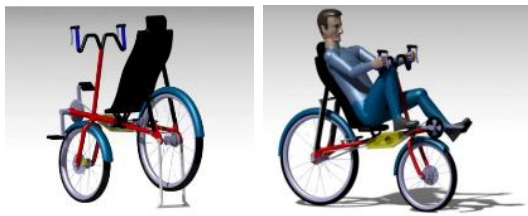

Fig. 1. Visualization of Urban Bicycle Concept. Left: rear-side view. Right: side view with rider

This bicycle concept (Fig.1.) have some differences from a typical commercially available recumbent bicycle. First, the riding posture is set more upright by $50^{\circ}$ from a horizontal line with $15^{\circ}$ for its frame. Second, the handlebar is using W shape. W shape will give more space for the knee while pedalling.

\subsection{Bicycle Specification}

Table 1. Specification result after CPD.

\begin{tabular}{|l|l|l|l|}
\hline \multicolumn{1}{|c|}{ Component } & \multicolumn{1}{|c|}{ Previous Specification } & Specification After CPD & Specification After CPD (Lightweight) \\
\hline Shifter & 7 speed & 3 Speed & 3 Speed \\
\hline Front Brake & Mechanical Discs Brake & Mechanical Discs Brake & Mechanical Discs Brake \\
\hline Rear Brake & V-Brake & V-Brake & V-Brake \\
\hline Brake Lever & Reverse Type & Road Type & Reverse Type \\
\hline Pedal & Al Alloy, Sealed Bearing & Al Alloy, Sealed Bearing & Al Alloy, Sealed Bearing \\
\hline Crankset & Al Alloy, 48T, single speed & Al Alloy, 48T, single speed & Al Alloy, 42T, single speed \\
\hline Bottom Brackets & Square Shaft, Sealed Bearing & Square Shaft, Sealed Bearing & Square Shaft, Sealed Bearing \\
\hline Chain & 7 speed & Single speed & 10 Speed, Hollow Link \\
\hline Front Rim & Al Alloy, 20", 32H & Al Alloy, 20", 36H & Al Alloy, 20", 32H \\
\hline Rear Rim & Al Alloy, 700c, 32H & Al Alloy, 700c, 36H & Al Alloy, 700c, 36H \\
\hline Front Hub & $32 \mathrm{H}, 6$ bolts Disc Brake & $36 \mathrm{H}, 6$ bolts Disc Brake & $32 \mathrm{H}, 6$ bolts Disc Brake \\
\hline Rear Hub & cassette 7 speed, 32H & Internal Gear 3 speed & Internal Gear 3 speed \\
\hline Front Tire & $20 " \mathrm{x} 1.5$ & $20 " \mathrm{x} 1.5$ & $20 " \mathrm{x} 1.25$ \\
\hline Rear Tire & $700 \times 28 \mathrm{c}$ & $700 \times 28 \mathrm{c}$ & $700 \mathrm{x} 25 \mathrm{c}$ \\
\hline Cassette & 7 speed & none & none \\
\hline Derailleur & 7 speed & none & none \\
\hline Head Set & $13 / 8$ Oversized & $13 / 8$ Oversized & $13 / 8$ Oversized \\
\hline Handle Bar & Custom & Custom, W shaped, Al Alloy & Bull Horn, Al Alloy \\
\hline
\end{tabular}




\begin{tabular}{|l|l|l|l|}
\hline \multicolumn{1}{|c|}{ Component } & \multicolumn{1}{|c|}{ Previous Specification } & \multicolumn{1}{c|}{ Specification After CPD } & Specification After CPD (Lightweight) \\
\hline Seat & Custom & Custom, plywood & Custom, plastic-Al Composite \\
\hline Chain Tensioner & Custom & Custom, Nylon & RD Pulley, CNC Al Alloy \\
\hline Main Frame & Custom & Custom, JIS G 3472 Round & Custom, JIS G 3472 Rectangular \\
\hline Fork & Custom & Custom, JIS G 3472 Round & Al Alloy 20" Folding Bike Fork \\
\hline Parking Stand & Custom & Custom, steel, upright & Custom, Steel, skewed \\
\hline
\end{tabular}

There are several changes in the specification of bicycle concept from the previous (as set in visual design) to after collaborative process [18] (Table 1.). The main change is on drive train which is the 7-speed groupset is no longer suitable and replaced by 3-speed Internal Gear. Internal Gear makes drivetrain become simpler and reduce chain length.

\subsection{Finite Element Model}

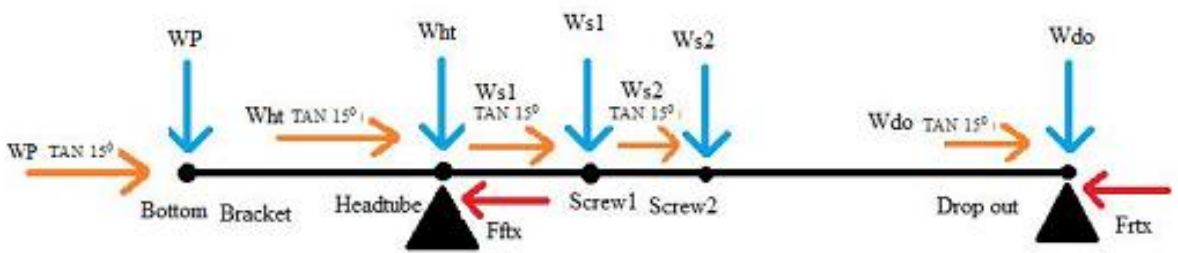

Where,

WP : Force exerted by foot to pedal

Wht : Force exerted by hand to head tube

Ws1 : Force exerted by body to seat at screw 1

Ws2 : Force exerted by body to seat at screw 2

Wdo : Force exerted by body to rear drop out

Frtx : Reaction force at horizontal direction

Fig. 2. Biomechanics model for a rider which rides the bicycle
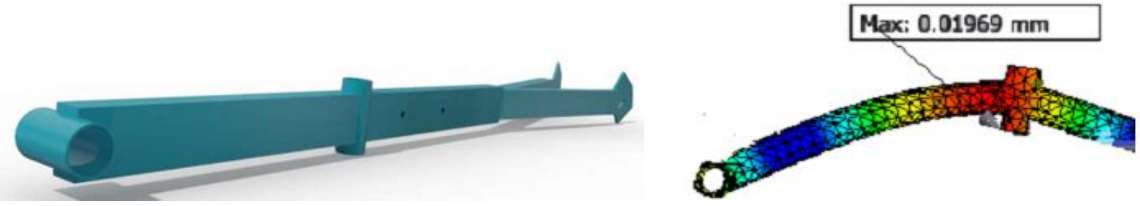

Fig. 3. Finite Element Simulation Example Result

Table 2. Summary of Finite Element Result.

\begin{tabular}{|l|c|c|c|c|}
\hline Cross Section (mm) & Wall Thickness (mm) & Safety Factor (ul) & Displacement (mm) & Mass (kg) \\
\hline$Ø 44.5$ (round) & 2.80 & $>15$ & 0.019 & 4.97 \\
\hline$\varnothing 44.5$ (round) & 3.05 & 14 & 0.034 & 5.16 \\
\hline$Ø 44.5$ (round) & 4.80 & $>15$ & 0.020 & 6.30 \\
\hline $30 \times 60$ (rectangular) & 1.30 & $>15$ & 0.057 & 4.00 \\
\hline 25x60 (rectangular) & 1.40 & $>15$ & 0.138 & 3.30 \\
\hline
\end{tabular}

On Fig. 2. Some assumption has been made for distributing body weight into several constraints $[19,20]$. We distribute body segment weight in two closest constraints and the magnitude is proportional to its distance from the constraints. The finite element simulation result can be seen in Fig. 3. And their summary is in Table 2. From the table, it can be seen that $30 \times 60 \mathrm{~mm}$ rectangular steel tube is the lightest bicycle material which still has good strength and stiffness. This frame weight is still $1 \mathrm{~kg}$ more weight than average steel roadster frame on the market which is around $3 \mathrm{~kg}$. 


\subsection{Physiological Test Result}
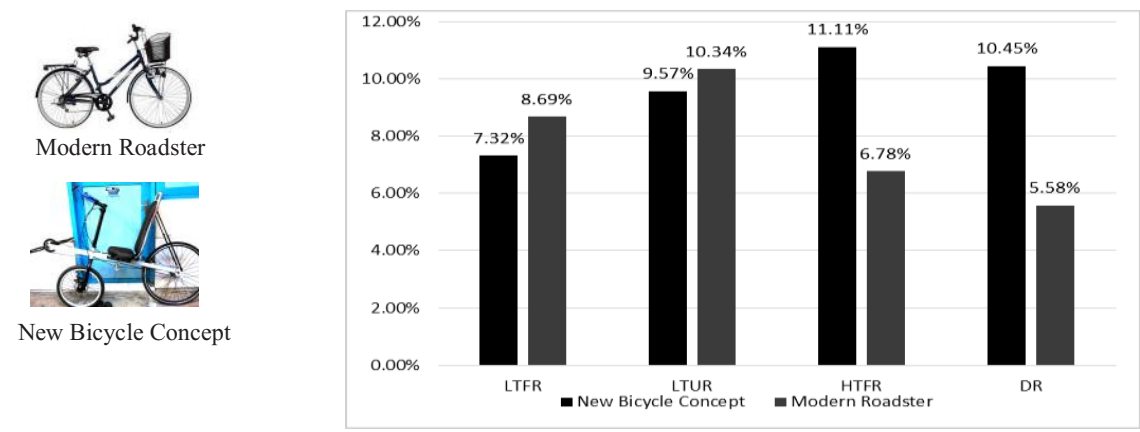

Fig. 4. Physiological (Cardiovascular Load) Test Result

Fig. 4. Shows the result of \%CVL for 20 subjects on 4 different terrain types, which is processed using \%CVL formula (1). From the graphic, it can be seen that the new bicycle concept can outperform the roadster on light traffic and up and down-road. These results prove that short wheelbase recumbent bicycle has more pedalling efficiency than roadster due to the rear wheel size and riding posture. Unfortunately, for heavy traffic and damage road, it becomes worse due to bicycle balance. Heavy traffic and damage road made the riders stop the bike several times and these cases gave difficulties for riding the recumbent. We found that subject still need many efforts when starting the recumbent even though we have trained them well. Our investigation led to rider's habits of using upright type bicycle which could not be washed out completely during the test.

\section{Conclusion}

This paper presents a comprehensive development of new urban bicycle concept, from requirement definition to prototype building. The new concept can outperform modern roadster type bicycle in light traffic road and up and downhill terrain. For stop and go usage, such as on heavy traffic road, the new concept still needs improvement in bicycle balance. Based on the overall test result, it can be concluded that the new bicycle concept is promising and still appropriate for the next development.

Acknowledgement: This paper and presentation is funded by Hibah Penelitian Unggulan Perguruan Tinggi from (PUPT) Ristek Dikti 2016 and Hibah Peningkatan Kapasitas Laboratorium Penelitian (PKLP) PNBP Universitas Sebelas Maret 2017.

\section{References}

1. C. Johansson, B. Lövenheim, P. Schantz, L. Wahlgren, P. Almström, A. Markstedt, M. Strömgren, B. Forsberg, J.N. Sommar, Impacts on air pollution and health by changing commuting from car to bicycle. Science of the Total Environment, 584-585, 55-63 (2017)

2. H.K. Epema, S. van den Brand, W. Gregoor, J.D.G. Kooijman, H.P. Pereboom, D.C. Wielemaker, C.-J. van der Zweep Bicycle Design: A different approach to improving on the world human powered speed records. Procedia Engineering, 34, 314-318 (2012) 
3. M. Ahillen, D. Mateo-Babiano, J. Corcoran, Dynamics of bike sharing in Washington, DC and Brisbane, Australia: Implications for policy and planning. International Journal of Sustainable Transportation, 10, 441-454 (2016)

4. D.C. Rehak, Cyclist's Hands Overcoming Overuse Injuries. Hughston Helath Alert, 15, $3(2003)$

5. J.M. Muyor, P. Minarro, A. Lopez, F. Alacid, Spinal Posture of Thoracic and Lumbar Spine Pelvic Tilt in Highly Trained Cyclist. Journal of Sport Science and Medicine, 10, 355-361 (2011)

6. I. Leibovitch, and Y. Mor, The Vicious Cycling: Bicycling Related Urogenital Disorder. European Urology, 47, 277-287 (2005)

7. H. Otani, M. Kaya, A. Tamaki, P. Watson, R.J. Maughan, Effects of solar radiation on endurance exercise capacity in a hot environment. European Journal of Applied Physiology, 116, 769-779 (2016)

8. J. DiGioia, K.E. Watkins, Y Xu, M. Rodgers, R. Guensler, Safety impacts of bicycle infrastructure: A critical review. Journal of Safety Research, 61, 105-119 (2017)

9. E. Kocabiyik. Engineering Concept in Industrial Product Design with A Case Study of Bicycle Design. Izmir Institute of Technology (2004)

10. T. Buchert, S. Neugebauer, S. Schenker, K. Lindow, R. Stark, Multi-criteria decision making as a tool for sustainable product development - Benefits and obstacles. Procedia CIRP, 26, 70-75 (2015)

11. M.C.Y. Tam, V.M.R. Tummala, An application of the AHP in vendor selection of a telecommunications system. Omega, 29, 171-182 (2001)

12. M. McGoldrick, Choosing The Right Bike for You. http://gobiking.ca/resourceshowto/choose-the-right-bicycle-for-you/ (2009)

13. A.L. Scwab, J.D.G. Koijman, On The Design of Recumbent Bicycle with A Perspective on Handling Qualities. IDETC/CIE (2012)

14. Fairuz, Bike to Work Polygon Heist 1.0 Hybrid Bicycle with Affordable Price (in Indonesian Language) https://fairuzelsaid.wordpress.com/2011/03/27/byke-to-workpolygon-heist-1-0-sepeda-hibrid-harga-terjangkau/ (2013)

15. K.T. Ulrich and S.D. Eppinger. Product Design and Development, $5^{\text {th }}$ Edition. McGraw-Hill (2012)

16. L. Herdiman, S. Susmartini, N. Adiputra, K. Tirtayasa, Application of Appropriate Technology in Ankle Joint to Below Knee Prosthetic Reduce Working Pulse on Transtibial Amputee. 7th WACBE World Congress on Bioengineering, 154-157 (2015)

17. B. Suhardi, I. Priadythama, M. Arief, Urban Bicycle Conceptual Development Considering Ergonomic Criteria (in Indonesia language), 12, Spektrum Industri, 231240 (2014)

18. B. Suhardi, I. Priadythama, C. W. Fitriyani, Design Specification Determination with Collaborative Approach for Indonesian Short Wheelbase Recumbent Bicycle, Applied Mechanics and Materials, 815, 298-303 (2015)

19. I. Priadythama, B. Suhardi, V. G. Rengganis, Standard Tube Selection for Recumbent Bicycle Frame Using Simulated Finite Element Analysis. Joint International Conference of Electric Vehicular Technology and Industrial, Mechanical, Electrical and Chemical Engineering (ICEVT \& IMECE), 5E1-1 (2015)

20. I. Priadythama, B. Suhardi, I. Adiasa, Further study on a short wheel base recumbent bike frame using simulated finite element analysis, International Conference of Industrial, Mechanical, Electrical, and Chemical Engineering (ICIMECE), (2016) 